\title{
Preparedness of Health Facilities in Chandigarh for Biological Disasters
}

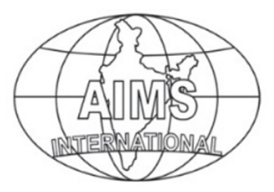

DOI: $10.26573 / 2018.12 .1 .3$

Volume 12, Number 1

January 2018, pp. 25-45

\author{
Gaurav Bhatia \\ Namrata Sandhu \\ Chitkara University \\ (fear_naught@hotmail.com) \\ (namrata.sandhu@chitkara.edu.in)
}

Disasters are the constant companions of mankind. Mostly, any talk on disasters centres around only natural disasters, with anthropogenically caused disasters not being given adequate credence. Utilising an exploratory approach and the World Health Organisation's Hospital preparedness checklist, this paper examines the preparedness of Chandigarh health facilities to combat incidents of Biological Disasters. The findings have been discussed under nine major heads - viz. Command and Control; Communication; Safety and Security; Triage; Surge Capacity; Continuity of Essential Services; Human Resource Development; Logistics and Supply Management and Post Disaster Recovery.

Keywords: Biological Disasters, Command and Control, Communication, Safety and Security, Triage, Surge Capacity, Continuity of Essential Services, Human Resource Development, Logistics and Supply Management and Post Disaster Recovery

\section{Disasters}

The Disaster Management Act 2005 defines disaster "as a catastrophe, mishap, calamity or grave occurrence in any area, arising from natural or manmade causes, or by accident or negligence which results in substantial loss of life or human suffering or damage to, and destruction of property, or damage to, or degradation of environment, and is of such a nature or magnitude as to be beyond the coping capacity of the community of the affected area". (Ministry of Law and Justice: Legislative Department, 2005). The geo-climatic condition and the high level of socioeconomic disparities obtaining in India, make it extremely disaster prone. (Kaul, Ayaz, \& Lohitkumar, 2005).Natural and anthropogenic ally caused disasters have been consistent companions of mankind and they need to be studied with a view to minimising their frequency and debilitating consequences.

The High Power Committee (HPC) on Disaster Management, 1999, segregated disasters into five distinct sub-groups viz. "Water and Climate-related; Geological related; Chemical, Industrial and Nuclear related; Accident related and Biological related Disasters".(National Centre for Disaster Management, 2002). Natural hazards have always attracted greater attention and focus - this fact is amply borne out by the fact that in common parlance whenever the term "disaster" is used it is usually expected to deal with one or the other type of natural geological disaster e.g. Floods, 
Earthquake, Landslide etc. In a significant departure from the existing cogitation, this paper focuses attention on the last subgroup - i.e. biologically related disasters and attempts to evaluate the preparedness of Health Facilities in Chandigarh to combat incidents of "biological disasters".

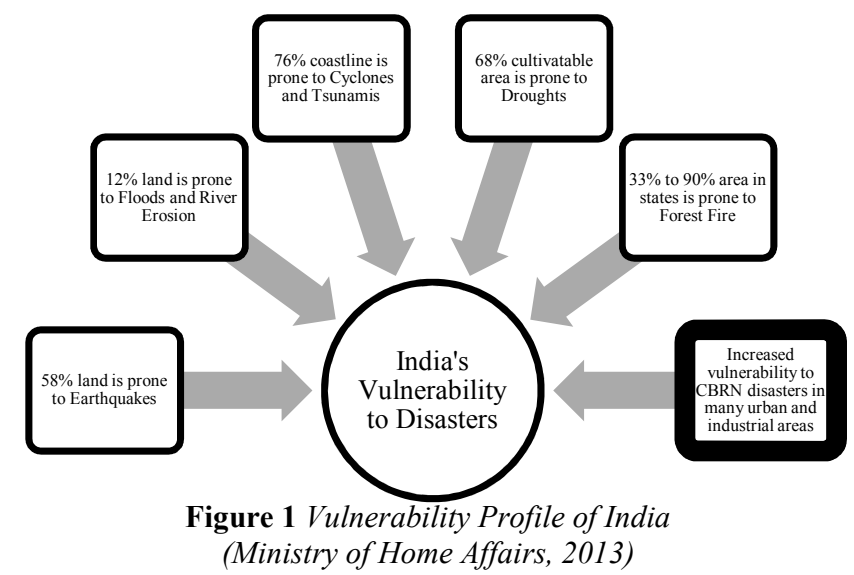

The National Disaster Management Authority, India defines the term Biological disasters as "scenarios involving disease, disability or death on a large scale among humans, animals and plants due to toxins or disease caused by live organisms or their products. Such disasters may be natural in the form of epidemics or of existing, emerging or re-emerging diseases and pestilences or man-made by the intentional use of disease-causing agents in Biological Warfare (BW) operations or incidents of Bioterrorism (BT)." (National Disaster Management Authority, 2008)

\section{The Ground Situation}

Disaster management is gaining importance both domestically and internationally. Nations all over the world have woken up to the necessity of building, enhancing and ensuring the resilience of their communities to disasters (United Nations International Strategy for Disaster Reduction, 2005a, 2005b). Lack of preparedness to combat disasters causes devastation and potentially impacts surrounding communities (Cole, 2009). Officials at the Centre, State and District level are tasked with preparing communities to face disasters. However, this preparedness is often restricted to Guidelines and SOP's with a very limited capability of executing actions on the ground. To effectively manage the aftermath of biological disasters and bioterrorist incidents, the city administration and health facilities would necessarily have to rely on the central government resources (Ryan \& Glarum, 2008). The "accidental" release of biological agents by its very nature cannot be avoided, but if the indicators leading up to the event are recognised adequately in advance - some, if not all the accidents may be prevented.

It is a foregone conclusion that without adequate preparation the quantum of damage and devastation suffered in the face of a biological agent release - by the population in Chandigarh would be unparalleled. The level of preparedness at the city/ municipal level are aspects which require being urgently addressed and assessed so that appropriate actions in terms of preparation, prevention and mitigation are put 
into motion. The problem this paper addresses is that without prior preparation for combating biological disasters, there could be untold devastation for local communities. The level of preparedness of existing government and private health facilities to combat biological disasters is the core issue that this paper addresses.

\section{Review of Literature}

Terrorists have progressively begun displaying an unprecedented "enthusiasm for higher levels of carnage, destruction and publicity" and though "there is no need to overreact" but at the same time it would be equally "ill-advised to seek comfort in denial" (D A Alexander \& Klein, 2006; David Alan Alexander \& Klein, 2003). CBRNe (Chemical Biological Radiological Nuclear and Explosive) (FEMA, 2009) terrorism in all probability will be a "significant threat in the twenty-first century" (Richardt \& Sabath, 2013). This threat may be further compounded by "potential Lone Actors or Autonomous Cells (LA/AC)" engaging in deleterious CBRNe activity - "calibrated to their CBRN ambitions, capabilities and calibre" (Ackerman \& Pinson, 2014).

A very large number of biological agents like - Anthrax, Botulism, Cholera, Plague, Q fever, Smallpox, Shigellosis, Tularemia, and Viral Haemorrhagic fever (Bupesh, Sivasubramanian, Sakthivadivel, Gunasekeran, \& Raman, 2014)-could be used as agents for creating biological disasters. It is imperative that "preparedness against these agents need complete knowledge about the disease, better research and training facilities, diagnostic facilities and improved public health system" (Thavaselvam \& Vijayaraghavan, 2010). Any such major biological disaster will evidently result in a Mass Casualty Incident (MCI) (FEMA, 2009); but as we all know too well - that "our nation's hospitals are not prepared to manage mass casualties...resulting from chemical or biological WMD (Weapons of Mass Destruction)" - which may, unfortunately "result in the loss of hundreds or even thousands of lives" (Bennett, 2006).

Whenever health facilities combat an MCI involving CBRNe agents, the basic utilitarian rule remains - "Do the greatest good for the greatest number of disaster victims in the light of limited resources". Moreover, the National vision for CBRNe Disaster management also specifies that we must endeavour to "prevent the incidence by taking all 'reasonably practical' technical safety and security measures" (Bhardwaj, 2010). In addition to this knowledge, the importance of "triage, decontamination, and treatment" to a first responder cannot be overstated and it is imperative to conduct a triage of the victims based on "available medical resources, casualty number, and severity of injury" (Ramesh \& Kumar, 2010). All CBRNe events are characterised by a rapid speed of onset necessitating an extremely "rapid and adaptive" response - failing which there would be severe "detrimental effects on the health and psychosocial (wellbeing) of the community" (Sandstrom, Eriksson, Norlander, Thorstensson, \& Cassel, 2014). It, therefore, follows that in order to minimise the damage which is likely to be caused due to a CBRNe event, it is essential to "plan and train" for such an eventuality since a very "high degree of specialist knowledge among responders" would be required to mitigate the effects of such a disaster. Lastly, a CBRNe incident will also have a "disproportionate effect on all aspects of efficient management of casualties" (Calder \& Bland, 2015).

In India, disaster management has traditionally been "reactive and relief centric". Government of India (Ministry of Law and Justice: Legislative Department, 2005) 
passed the Disaster Management (DM) Act - 2005, to usher in an era of a more integrated, proactive and holistic approach with Prevention, Mitigation and Preparedness - being the three pillars on which this edifice is supported. Thus, the importance of evaluating the present levels of preparedness of health facilities to combat biological disasters cannot be overemphasised - and hence there lies the necessity of this paper.

\section{Research Methodology and Design}

An Exploratory Study approach was adopted to empirically ascertain and arrive at a better understanding of the ground situation, about whether the "Health facilities in Chandigarh were prepared to face biological disasters?" There is an insignificant amount of previous research on the subject at hand - especially within the Indian context and this approach was considered appropriate to understand the varied dimensions of the problem. Capitalising upon the inherent flexibility and adaptability to mid-course correction provided by this approach, the paper examined the specific issue of preparedness of Chandigarh against biological disasters. The effective management of a potential biological disaster situation is primarily contingent on the existence of well-rehearsed plans, Standing Operating Procedures (SOP) and effective knowledge and utilization of all organic and inorganic resources - which obviously will have to be kept in a state of readiness at all times and must be capable of being identified and evaluated on an as required basis (J. R. Ryan 2016).

The wide variety of biological agents available in the world today brings us to the imponderable eventuality that a hitherto unknown biological agent may be utilized for the very first time in a biological strike. This brings to the fore another aspect of the already identified literature gap wherein not only are there negligible studies which examine this issue, the situation gets further compounded for the local government and administrative authorities who must have an established methodology to tackle a biological disaster or bioterrorist incident occasioned due to the use of a hitherto unknown biological agent (M. Giblin, Schafer, and Burruss 2008). Further, this paper concurrently evaluated the specific needs and limitations of Chandigarh to face biological disasters vis a vis the Emergency Management measures existing in the city with respect to effectively tackling the consequences of a biological disaster or bioterrorist incident. Having evaluated these aspects - in case the conclusion drawn indicates that the existing levels of training, awareness, knowledge of mitigation measures, availability of organic and inorganic resources and personnel are insufficient - that would indicate unequivocally that Chandigarh is NOT prepared to face a biological disaster or bioterrorist incident (M. Giblin, Schafer, and Burruss 2008).

The methodology followed in the seminal study titled "Hospital Preparedness for Victims of Chemical or Biological Terrorism" (Wetter, Daniell, \& Treser, 2001) conducted for four North Western states in USA by Lt Cdr Donald Clark Wetter et al in 2001, was the base document which was referred to by the author to seek guidance with respect to the finer nuances of conducting this study for evaluating the health facilities preparedness for biological disasters in Chandigarh. 


\section{Questionnaire Design}

Hospitals and other health facilities perform a vital role in making essential medical facilities available to communities during all types of disasters. This becomes even more relevant in the case of biological disasters - wherein the net result is often an unprecedented surge in the quantum of patients reporting for actual and perceived disabilities. Depending on the type of disaster in question, this sudden administrative load can quickly overwhelm any hospitals operational limits, thereby bringing the services being provided to a grinding halt. This dynamic situation needs to be understood in all its hues to be able to avoid a "self-goal" by not being up to the task of handling the consequences of the MCI. In order to collate the responses of the various health facilities in Chandigarh with respect to their preparedness for a biological disaster - an extensive study of the varied Checklists and Preparedness guidelines available online from Centre for Disease Control and Prevention (CDC http://www.cdc.gov) (Centre for Disease Control and Prevention/: CDC, 2002); Federal Emergency Management Agency (FEMA -https://www.fema.gov) (FEMA Federal Emergency Management Agency, 2014); World Health Organisation (WHO -http:/www.who.int) (Sorensen et al., 2011); International Criminal Police Organization (ICPO-INTERPOL - http://www.interpol.int) (ICPO - Interpol, 2007);

National Disaster Management Authority (NDMA - http://www.ndma.gov.in) (National Disaster Management Authority, 2013; National Executive Council (NEC) - Ministry of Home Affairs/: Government of India, 2013) was undertaken.

Based primarily on an extensive literature review, knowledge acquired during military service and in large measure, the WHO - Hospital Emergency Response Checklist (Sorensen et al., 2011) - a closed-ended questionnaire was generated and structured around nine Key Components (viz. Command and Control; Communication; Safety and Security; Triage; Surge Capacity; Continuity of Essential Services; Human Resource Development; Logistics and Supply Management and Post Disaster Recovery) - to evaluate the preparedness of the health facilities in Chandigarh against biological disasters and bioterrorist incidents. To assess whether or not Chandigarh is prepared to effectively combat a potentially disastrous situation arising due to biological disasters was contingent on the exact knowledge of what resources are available as compared to those required to tackle the emergent situation. This data was gleaned from the existing Disaster Management Plans for Chandigarh (Chandigarh Administration, 2015a; Chandigarh Disaster Management Authority, 2014). This data was further built upon by means of information generated during personal semi-structured interviews and administration of pre-prepared questionnaires to Administrative Heads and Medical professionals of the health facilities existing in Chandigarh.

The data utilised in this paper was primarily collected using Stratified NonProbability sampling by administering a closed-endedpre-prepared questionnaire to the Administrative Head(s), H(s)oD, Doctor(s) on Duty (as per availability) in government and private health facilities. In order to ensure adequate geographic dispersion, a wide cross section of health facilities available in Chandigarh were targeted. Amongst the government health facilities, data was collected from Bhai Ghiani Institute of Health Sciences (BGIHS - Sector 14), Post Graduate Institute of Medical Education and Research (PGIMER), Government Medical College and Hospital (GMCH - Sec 32), Government Multi-Specialty Hospital (GMSH - Sec 
16), Command Hospital - Chandimandir, Indo Tibetan Border Police (ITBP) Composite Hospital, Zirakpur and Headquarter 474 Engineer Brigade Polyclinic, Baltana. On the other hand only, those private health facilities were approached which stood accredited with the National Accreditation Board for Hospitals and Healthcare (NABH), in Chandigarh (Mukat Hospital - Sector 34A, Chaitanya Hospital - Sector 44), and the immediate surrounding areas i.e. Mohali (Max Hospital - Phase VI, Fortis - Phase VIII, Grecian Super Specialty Hospital, Ivy Hospital - Sec 71) and Panchkula (Alchemist - Sector 21).

\section{Challenges and Limitations}

During the course of the literature review, finding appropriate study material to get a comprehensive idea about the topic under examination was a significant challenge. The internet, online citation databases and online journals were the only succour. During the data collection phase, while interacting with the - administrators and doctors in the government and private health facilities - the author encountered an implausible quantum of officialdom, delaying tactics coupled with red-tapism. The task of approaching and seeking answers to pointed questions about the level of preparedness of a health facility often resulted in a significant amount of obfuscation and reluctance being exhibited by the respondents. The evaluation of the preparedness level of the health facilities was based on a "self-administered" questionnaire survey, which was fraught with the intrinsic risk of reporting an error and /or bias. Since, the personnel attempting the questionnaires were Doctors and Administrators of the health facility under evaluation, it was likely that their assessment may have been overly positive to their own advantage. Hence the "positives" with respect to the varied preparatory actions being undertaken by the varied health facilities needs to be taken with a pinch of salt.

The major difference in various government and private health facilities responding to the questionnaire - lay in the fact that in nearly all the private health facilities the task of interacting with an external agency on matters related to preparedness, was entrusted to the Quality Control department (usually headed by a Doctor), who responded to the questionnaire. However, in most government health facilities, usually the Medical Superintendents office was entrusted with the responsibility of commenting upon the preparedness levels of the facility. This was done differently by different government health facilities i.e. in some facilities only the Medical Superintendent answered the questionnaire, whereas in others the task was delegated to the various Heads of Department depending on their respective involvement in the emergency preparedness plan. Lastly, the atypical nature of the study, often resulted in an expression of scepticism - which was sometimes more eloquent than the answers the respondents wished to share.

\section{Chandigarh - Government and Private Health Facilities}

In order to fully understand the actual level of preparedness of government health facilities existing in Chandigarh, it was important to understand the basic characteristics of the city. According to 2011 census (Chandigarh Administration, 2015b; Government of India, 2011), the population of Chandigarh is 10.5 lakhs of which 2.83 lakhs is slum/rural population Chandigarh provides all three levels in healthcare delivery i.e. primary, secondary as well as tertiary. There are 16 sub- 
centres, 52 civil dispensaries offering Allopathic, Ayurvedic and Homeopathic OPD medical services, seven Alternative Medical Units, three Urban Primary Health Centres, two 50 bedded Community Health Centres, one 100 bedded Civil Hospital, one 500 bedded Govt. Multi-Specialty Hospital, one Govt. Medical College and Hospital and one PGIMER (Indiatimes.com, 2015). The city has successfully and effectively implemented the Hospital Management and Informative System (HMIS) and the Mother and Child Tracking System (MCTS).

In order to match up to the diverse medical requirements of the people of the city, many private hospitals in Chandigarh have been created. Nearly all the hospitals offer 24-hours facilities and services to the patients. Replete with emergency wards, coronary care unit, burns unit, intensive care unit, and neonatal intensive care unit, the hospitals in Chandigarh maintain a good medical and health standard. Besides most of the private hospitals have a large variety of specialized departments. Today, many of the health facilities in Chandigarh are among the top-rated hospitals in their respective specializations like Gastroenterology, Nephrology and Prosthetics are among the finest. Chandigarh is also well on its way to soon emerge as an important hub for medical tourism in North India.

\section{National Accreditation Board for Hospitals and Healthcare Providers (NABH)}

In order to keep the scope of the study manageable, only those private hospitals which have an NABH accreditation were included for evaluation of their preparedness against biological disasters and bioterrorism incidents. National Accreditation Board for Hospitals and Healthcare Providers (NABH) is the operational arm of the board of Quality Council of India (QCI), which operates a robust accreditation programme for healthcare establishments. The vision of NABH is to be an apex healthcare certification and quality improvement organization, operating at par with global best practices and standards. The approval of International Society for Quality in Health Care (ISQua) authenticates that NABH standards are in consonance with the global benchmarks set by ISQua. The hospitals accredited by NABH automatically achieve international recognition. Till now, hospital standards of only 11 nations (Australia, Canada, Egypt, Hong Kong, Ireland, Japan, Jordan, Kyrgyz Republic, South Africa, Taiwan and the United Kingdom) were accredited by International Society for Quality in Health Care (ISQua). India is the latest entrant to this exclusive club as its $12^{\text {th }}$ member country.

\section{Health Facilities and Disaster}

In a disaster situation, health facilities will play a vital role within the health care structure by providing critical medical care to the dependent community. Any incident that causes an MCI coupled with the loss of infrastructure and/or patient surge will necessitate the administration to swing into action, with a dynamic multijurisdictional / multi-functional reaction and recuperation effort, which must incorporate the provision of social health care. Without suitable advance crisis planning, local health care structures are bound to be overwhelmed and overburdened while attempting to provide care to the varied casualties resulting due to a critical event. Hospital crisis administration is a dynamic process requiring consistent efforts to ensure synergy between the neighbourhood and national health 
services. For any health facility to be able to achieve its stated aim, it is essential that its overall preparedness must be generic, applicable to a range of contingencies and necessarily based on an all-hazards approach. Such an all-encompassing preparedness must also be able to supplement existing emergency-management plans while executing all actions as per specific laid down standard operating techniques, which should be available even during normal routine operation.

\section{Use of Biological Agents}

Biological agents have been used since 1500 BC (Richardt \& Sabath, 2013) as surreptitious weapons which have the unique dual capacity of instilling a sense of dread and doom amongst any community while simultaneously achieving the desired social, economic and political goals of the perpetrators. The major reasons for their preference as a favourite weapon by terrorists and inimical forcesare primarily because of their "arduous detection, as well as postponed appearance - hours and days after the terrorist's attack". The fact that there is almost always a strong probability of secondary dissemination of the biological agent used - makes them a "go to" option for the empowered terrorist. In addition to the significant characteristics of biological agents (lethality, virulence, infectivity, stability, incubation period and transmissibility/contagiousness) the following important salient's transformed them into the terrorists' favourite weapon (Tonev, Kanev, \& Dishovsky, 2010). In comparison with chemical and atomic weapons, biological weapons are vastly less expensive and eminently more easily obtainable. According to the National Disaster Management Authority, India; biological agents are often referred to as "the poor man's atomic bomb"; since for near similar levels of mass casualty on unprotected community population, the comparable costs would be $\$ 2,000$ per square $\mathrm{Km}$ with conventional weapons, $\$ 800$ with nuclear weapons, \$ 600 with nerve gas weapons and just $\$ 1$ with biological weapons (National Disaster Management Authority, 2008).

- Biological agents could be used in minuscule quantities to achieve the same level of destruction as other conventional means, for e.g. to cause mass casualty event in an area of one square Km about 1800 pounds of conventional explosive would be required, but the equivalent mass casualty could be achieved by spreading only $1 / 4$ ounce Anthrax spores.

- Detection of biological agents is usually a herculean task, especially prior to their usage.

- The varied "incubation times" for diverse biological agents may result in the symptoms/consequences of the spread of the biological agent being visible from hours to days to weeks - after the actual dissemination.

- The actual process whereby any biological agent could be converted for use as a virulent agent of mass destruction is easily available off the Internet.

\section{Demographic Profile of the Study}

A total of 44 individual responses were collated for the study. Total of 29 questionnaires were responded to by government health facilities and 15 by private NABH accredited health facilities. The study collected the basic essential data 
related to identity, age, gender, educational qualification, role and contact details of each respondent.

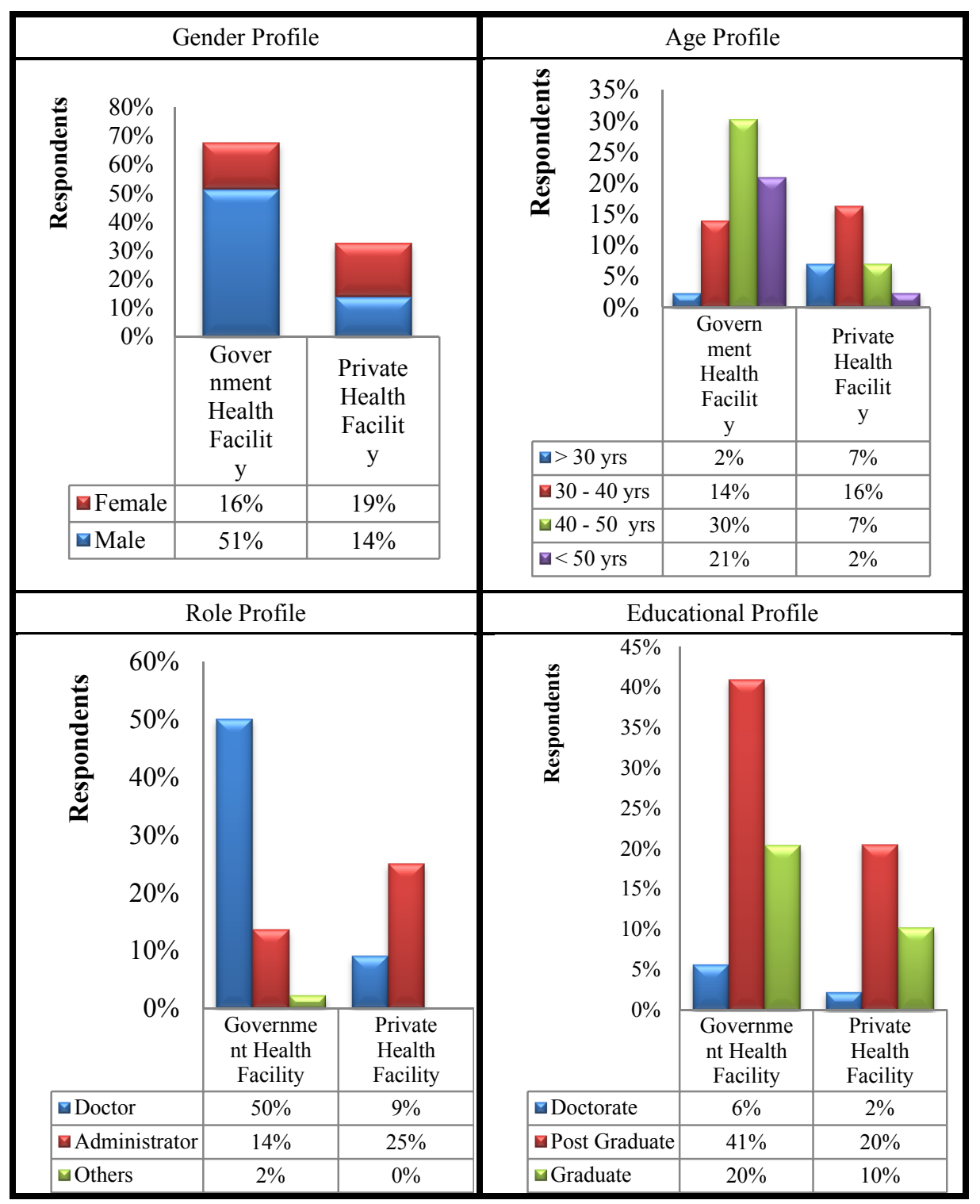

Figure 2 Demographic Profile

(Field Survey, January - April 2017)

\section{Findings}

The findings of the study have been segregated into nine distinct Key Components which together form the bedrock of assessing the preparedness of the health facilities to face biological disasters. These are - Command and Control; Communication; 
Safety and Security; Triage; Surge Capacity; Continuity of Essential Services; Human Resource Development; Logistics and Supply Management and Post Disaster Recovery.

\section{Command and Control}

"A well-functioning command-and-control system is essential for effective hospital emergency- management operations". (Sorensen et al., 2011). Such an Incident Command System would normally comprise of the following four major components, namely - Operations, Planning, Logistics, Finance/ Administration.

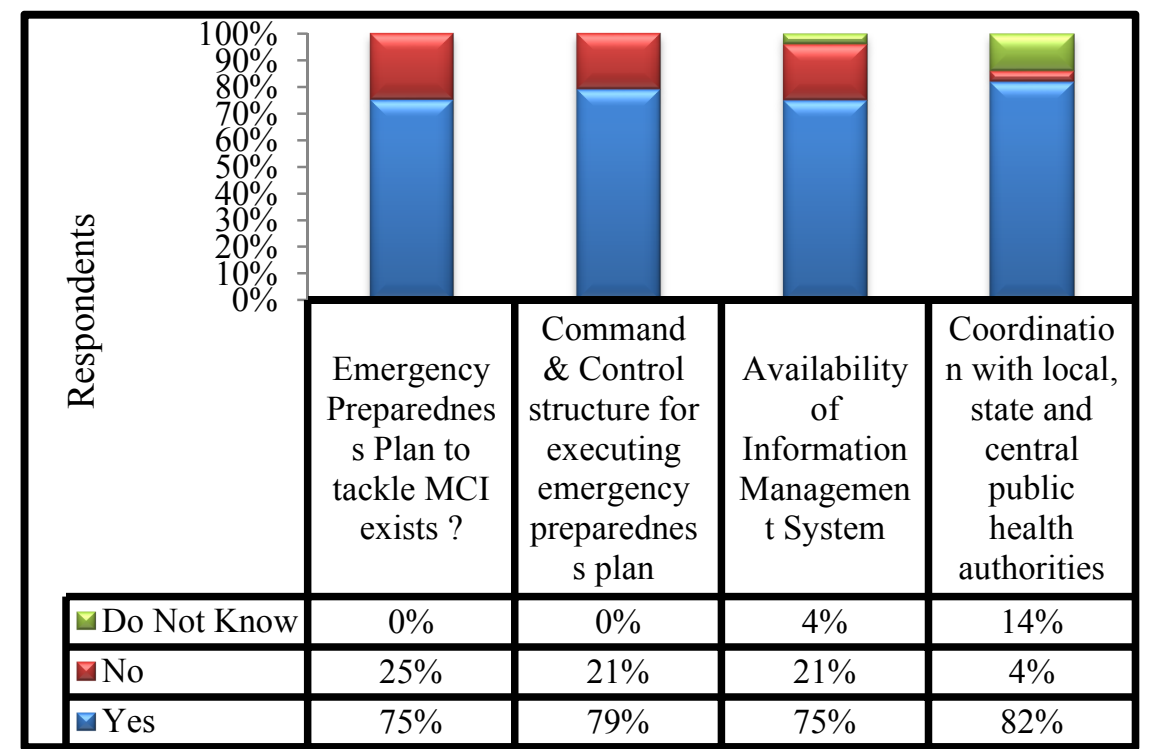

Figure 3 Command and Control

(Field Survey, January - April 2017)

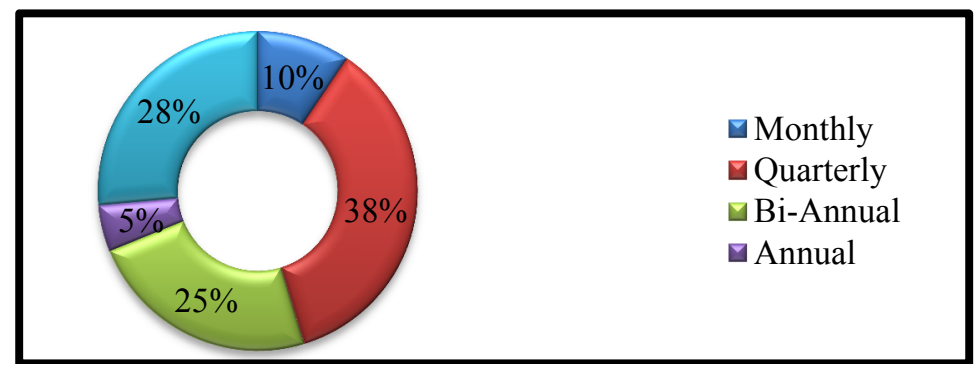

Figure 4 Execution and Updation of Emergency Plans

(Field Survey, January - April 2017)

The respondents were required to rank six aspects - namely planning and preparedness, communications, logistics and supply, equipment, training and technical advice/information - important for the effective execution of the health facilities emergency plan on a sliding scale from 1 to 6 . Each of these aspects was 
given a weight and the responses received were calculated to deduce the weighted rank average for each factor. Out of 44 responses collated only 33 valid responses were utilised to arrive at the decision of the weighted rank average. The calculated weighted ranks for the six aspects are presented in the following Table.

Table 1 Weighted Rank Average of Essential Factors (Field Survey, January - April 2017)

\begin{tabular}{|l|c|c|}
\hline \multicolumn{1}{|c|}{ Factors } & Weight Assigned & Weighted Rank Average \\
\hline Planning and Preparedness & 6 & 136 \\
\hline Communications & 2 & 123 \\
\hline Logistics and Supply & 3 & 114 \\
\hline Equipment & 4 & 113 \\
\hline Training & 5 & 94 \\
\hline Technical Advice / Information & 1 & 92 \\
\hline
\end{tabular}

On the question of rating the health facilities ability to manage victims of biological disasters, all respondents provided a consistently good score. It is evident from the data that a majority $(50 \%)$ of the respondents rate their health facilities capability as "Fair", while only $34 \%$ rate themselves as "Good".

\section{Communication}

"Clear, accurate and timely communication is necessary to ensure informed decisionmaking, effective collaboration and cooperation, and public awareness and trust" (Sorensen et al., 2011). This component judged the effectiveness of communication of the respective health facilities on the aspect of how the plan is initiated, whether the health facility has a Public Information spokesperson and how the various functionaries are recalled to the hospital. In response to the question of how the emergency preparedness plan is initiated, there were primarily four different responses. Only $61 \%$ of the respondents chose to answer this question. The valid responses received varied from code-based activation (37\%), usage of telephone (4\%), usage of mass communication means $(41 \%)$ or no plan/blank $(19 \%)$. The fact that $39 \%$ of the respondents from amongst the health facilities evaluated either did not have a plan or did not know about it - clearly indicates that there is a fair amount of flux which exists in this important aspect of initiation of the plan - which would obviously be the start point for the effective control of the biological disaster emergency.

The availability of the Public Information Officer (PIO) / spokesperson tasked with the job of interacting with the media and answering the relevant queries by the public evoked a mixed response. Nearly all private and government health facilities had a dual-tasked PIO who was tasked with tackling the public queries. $73 \%$ of the respondents acknowledged the availability of a PIO, while $14 \%$ responded in the negative and an equal percentage was found to be unaware. There was a total of six options to indicate the manner in which the medical personnel and staff of the health facility were being notified about the initiation of the emergency plan. The respondents were permitted to indicate multiple channels being used for this purpose. 
All respondents attempted this question. The most preferred option to notify the medical staff and personnel of the health facility was by using the telephone/mobile (41\%), followed by the usage of a Public-Address system (28\%) and the third most popular option being used was by SMS / bulk SMS (19\%) being sent to the staff.

\section{Safety and Security}

"Well-developed safety and security procedures are essential for the maintenance of hospital functions and for incident response operations during a disaster" (Sorensen et al., 2011). The most alarming figures were evinced for the question of availability of protective gear and availability of a designated area for isolation of the contaminated casualties - wherein $55 \%$ and $57 \%$ of the respondents answered negatively, respectively. Moreover, a consistently high percentage of the respondents (varying from $5 \%$ to $23 \%$ ) were unaware of the various Security and Safety measures being implemented in the health facilities. These are thus, the areas where improvement of standards is immediately warranted.

\begin{tabular}{|c|c|c|c|c|c|}
\hline \multirow{2}{*}{\multicolumn{2}{|c|}{$\begin{array}{r}100 \% \\
90 \% \\
80 \% \\
70 \% \\
60 \% \\
50 \% \\
40 \% \\
30 \% \\
20 \% \\
10 \% \\
0 \%\end{array}$}} & $\square$ & $\Rightarrow$ & 7 & 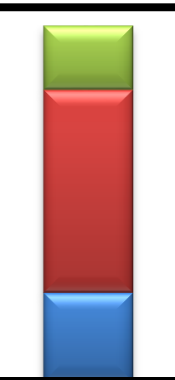 \\
\hline & & $\begin{array}{l}\text { Availability } \\
\text { of bio } \\
\text { protection } \\
\text { gear? }\end{array}$ & $\begin{array}{c}\text { Security } \\
\text { setup to } \\
\text { ensure order } \\
\text { and discipline } \\
\text { during MCI }\end{array}$ & $\begin{array}{l}\text { Security } \\
\text { related help } \\
\text { from } \\
\text { government } \\
\text { and / or } \\
\text { private } \\
\text { security } \\
\text { agencies }\end{array}$ & $\begin{array}{l}\text { Designated } \\
\text { area for } \\
\text { isolation of } \\
\text { CBRN } \\
\text { related } \\
\text { casualties }\end{array}$ \\
\hline & Do Not Know & $11 \%$ & $5 \%$ & $23 \%$ & $18 \%$ \\
\hline & No & $55 \%$ & $18 \%$ & $11 \%$ & $57 \%$ \\
\hline & Yes & $34 \%$ & $77 \%$ & $66 \%$ & $25 \%$ \\
\hline
\end{tabular}

Figure 5 Safety and Security

(Field Survey, January - April 2017)

\section{Triage}

"Maintaining patient triage operations, on the basis of a well-functioning masscasualty triage protocol, is essential for the appropriate organization of patient care" (Sorensen et al., 2011). The figures in this area of preparedness were across the board quite encouraging since the health facilities evaluated consistently scored $80 \%$ or above in various aspects relevant to the Triage facilities available in the health facilities. Albeit a high percentage of respondents gave a negative answer to the 
availability of a contingency site for Triage $(19 \%)$ and method of patient Triage identification (15\%). These figures along with the absence of knowledge about Triage protocols in the health facilities - are areas where further improvement can be instituted.

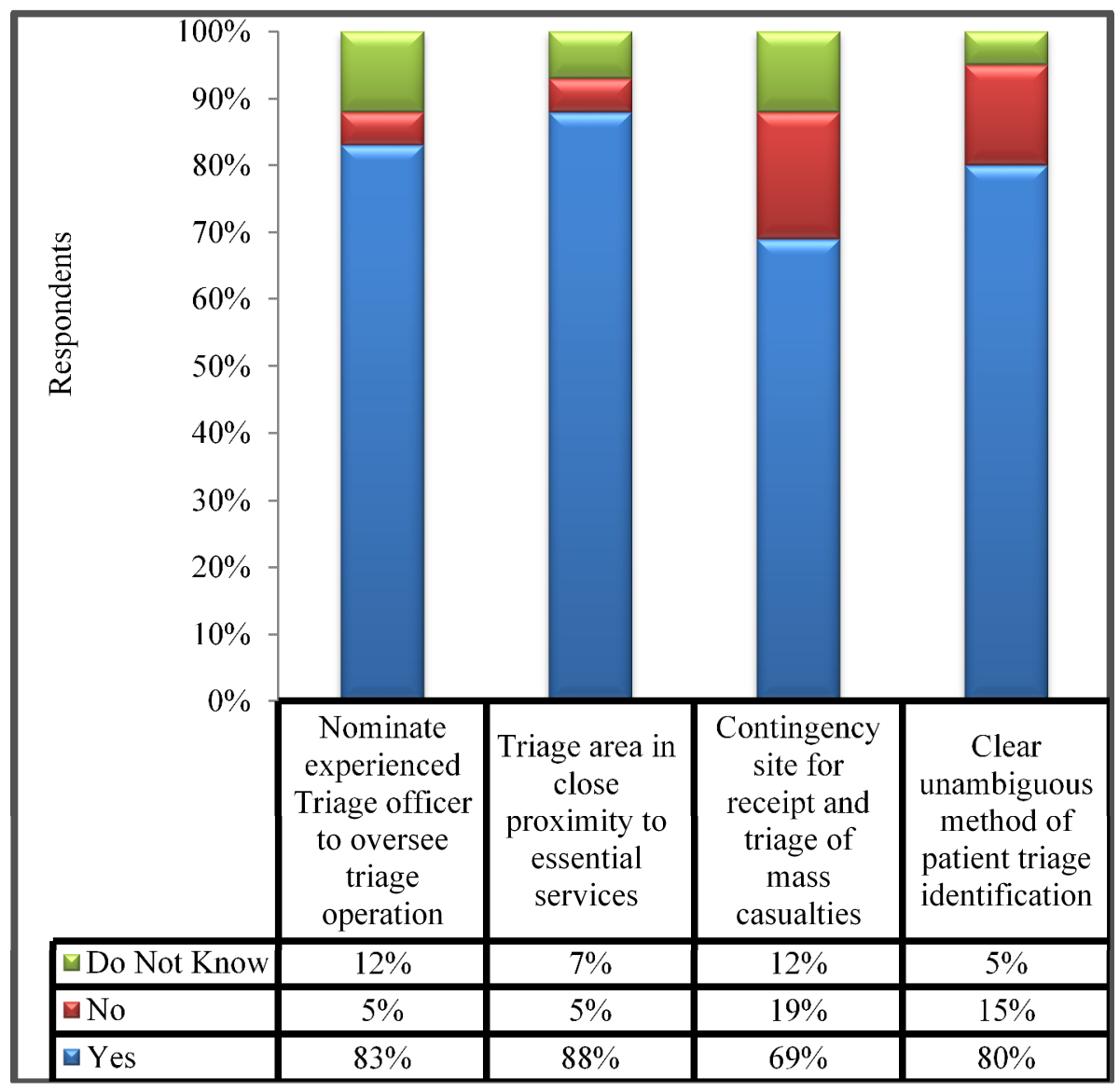

Figure 6 Triage

(Field Survey, January - April 2017)

\section{Surge Capacity}

"Surge Capacity - defined as the ability of a health service to expand beyond the normal capacity to meet increased demand for clinical care - is an important factor of hospital disaster response and should be addressed early in the planning process" (Sorensen et al., 2011). A total of four questions were posed to the respondents to assess their knowledge about the existing arrangements for Surge capacity in their respective health facilities. The level of general awareness about the licensed capacity vs. the planned surge capacity of the hospital left a lot to be desired. $45 \%$ of the respondents were not aware of the exact figures and gave no response. The knowledge about where the additional patient inflow would get accommodated in case of an MCI was satisfactory with $86 \%$ of respondents identifying specific areas. 
Corridors (50\%) and Waiting Halls (75\%) emerged as the two most common locations for accommodating the patient surge. This then follows that these areas must be kept free of clutter and must be always managed in a manner that there use for patient surge is facilitated in times of crisis. The responses to the balance two questions for this key component are tabulated hereunder for ease of assimilation.

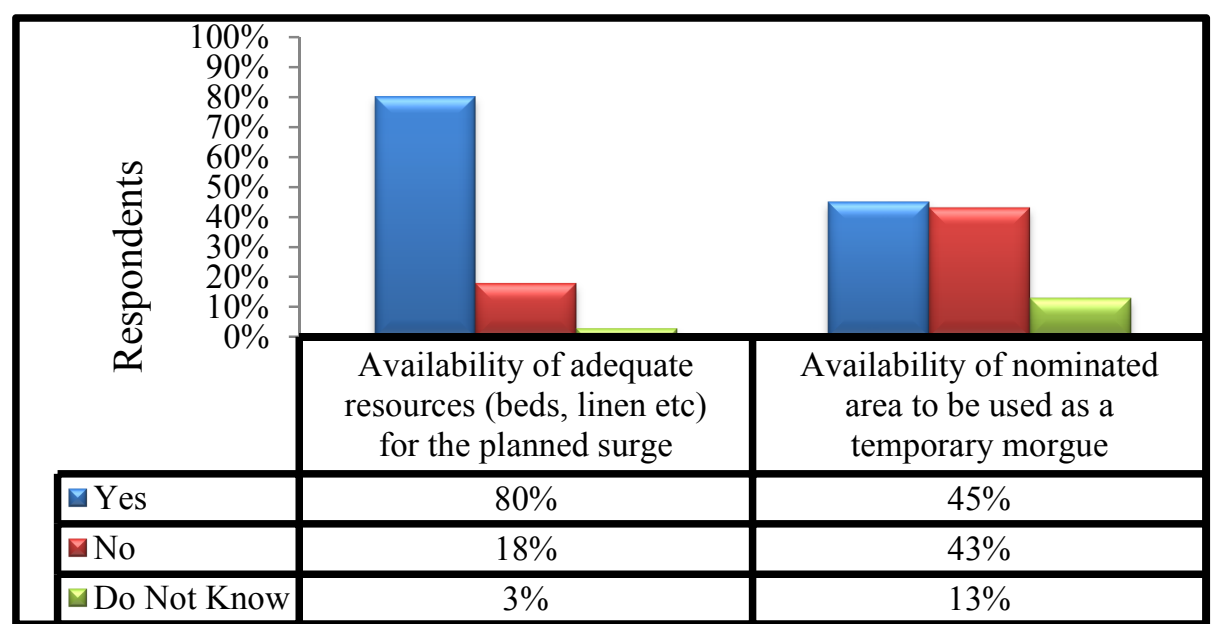

Figure 7 Surge Capacity

(Field Survey, January - April 2017)

\section{Continuity of Essential Services}

"A disaster does not remove the day-to-day requirement for essential medical and surgical services (e.g. emergency care, urgent operations, maternal and child care) that exists under normal circumstances. Rather, the availability of essential services needs to continue in parallel with the activation of a hospital emergency response plan" (Sorensen et al., 2011). Apart from the fact that a fairly large number of respondents did not know specific details pertaining to Continuity of Essential Services (19\% and 16\% respectively), what was even more surprising was that only $57 \%$ of the health facilities had an early inpatient discharge protocol, whereas $24 \%$ did not. On the other hand, $49 \%$ of the health facilities had no MoU with nearby health facilities for accepting patient overflow in case of a crisis. These aspects need to be remedied.

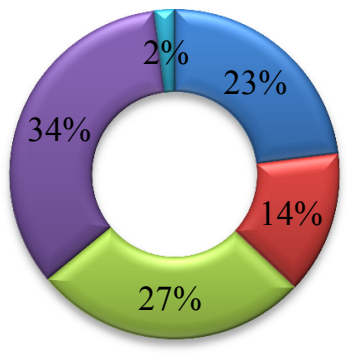

$\square$ Upto 250

๑250-500

$\square 500-1000$

$\square$ More than 1000

$\square$ Do Not Know 


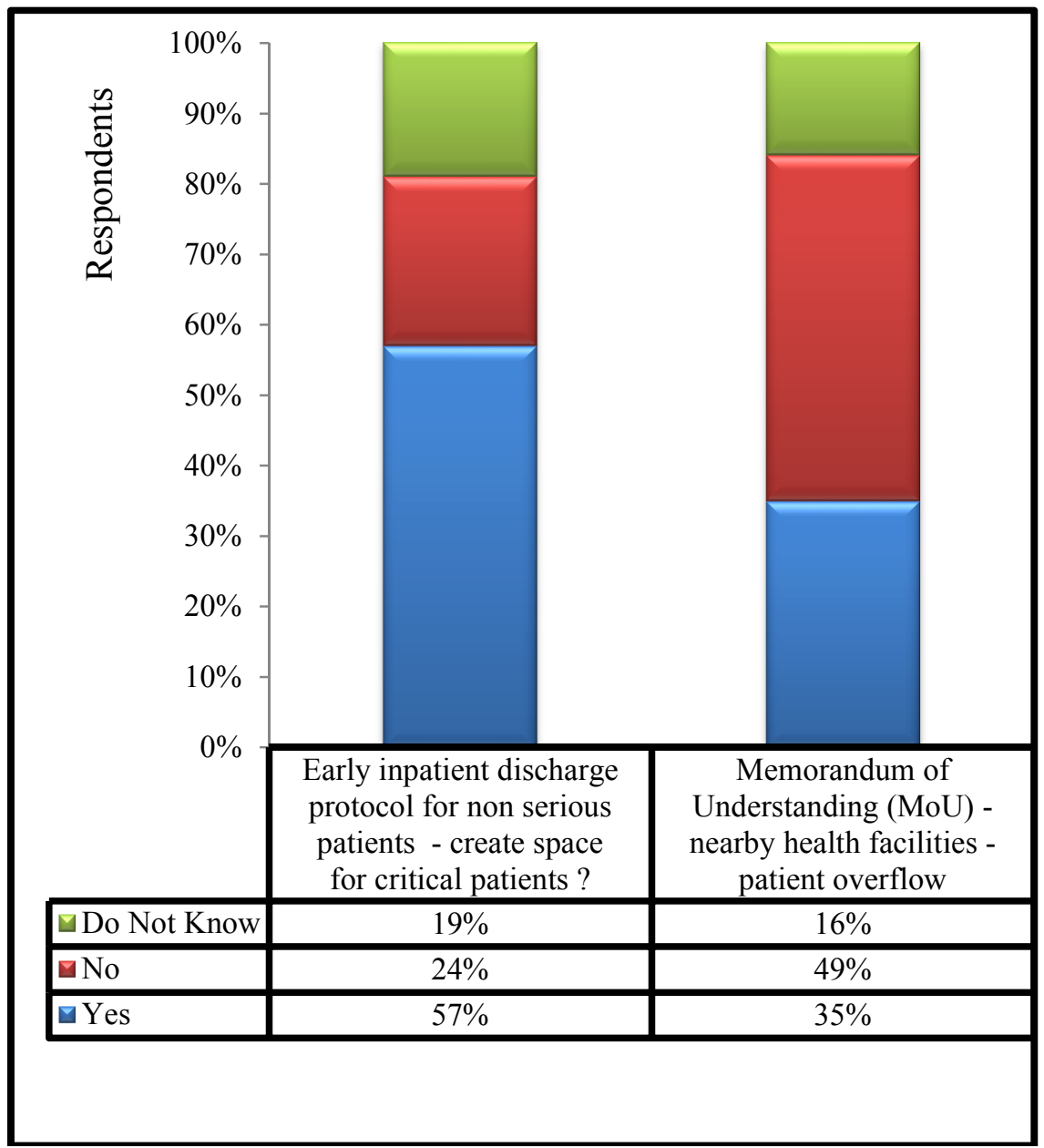

Figure 8 Continuity of Essential Services: Average Daily OPD

(Field Survey, January - April 2017)

\section{Human Resource Development}

"Effective human resource management is essential to ensure adequate staff capacity and the continuity of operations during an incident that increases the demand for human resources" (Sorensen et al., 2011). The significant answers emerging are the fact that only $45 \%$ of the health facilities conduct any training for combating incidents of biological disasters and bioterrorism. A total of $52 \%$ respondents confirmed that a combination of theoretical and practical training was being conducted. On the other hand, a similar percentage (45\%) of the respondents evinced ignorance about the actual periodicity of the training being conducted. These two figures appear incongruous to each other. 


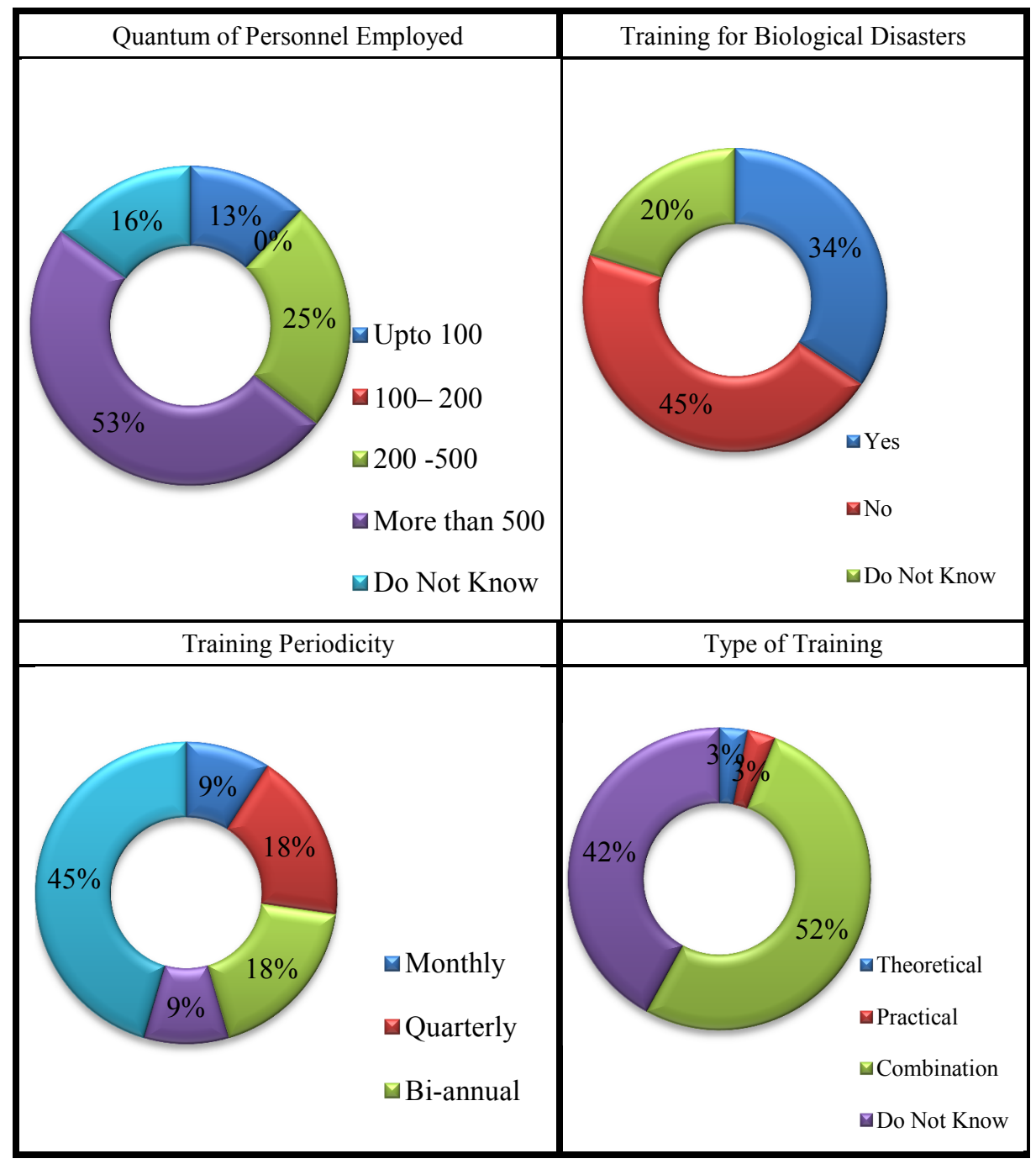

Figure 9 Human Resource Development

(Field Survey, January - April 2017)

\section{Logistics and Supply Management}

"Continuity of the hospital supply and delivery chain is often an underestimated challenge during a disaster, requiring attentive contingency planning and response." (Sorensen et al., 2011). The healthy figure of $77 \%$ of the health facilities confirming that antibiotics and supplies for combating an MCI were stockpiled on their respective premises was indeed encouraging. Further, the fact that nearly $75 \%$ of the health facilities could ensure resupply of critical antibiotics etc in a 24-hour cycle was also a good step towards complete preparation for any disaster. 

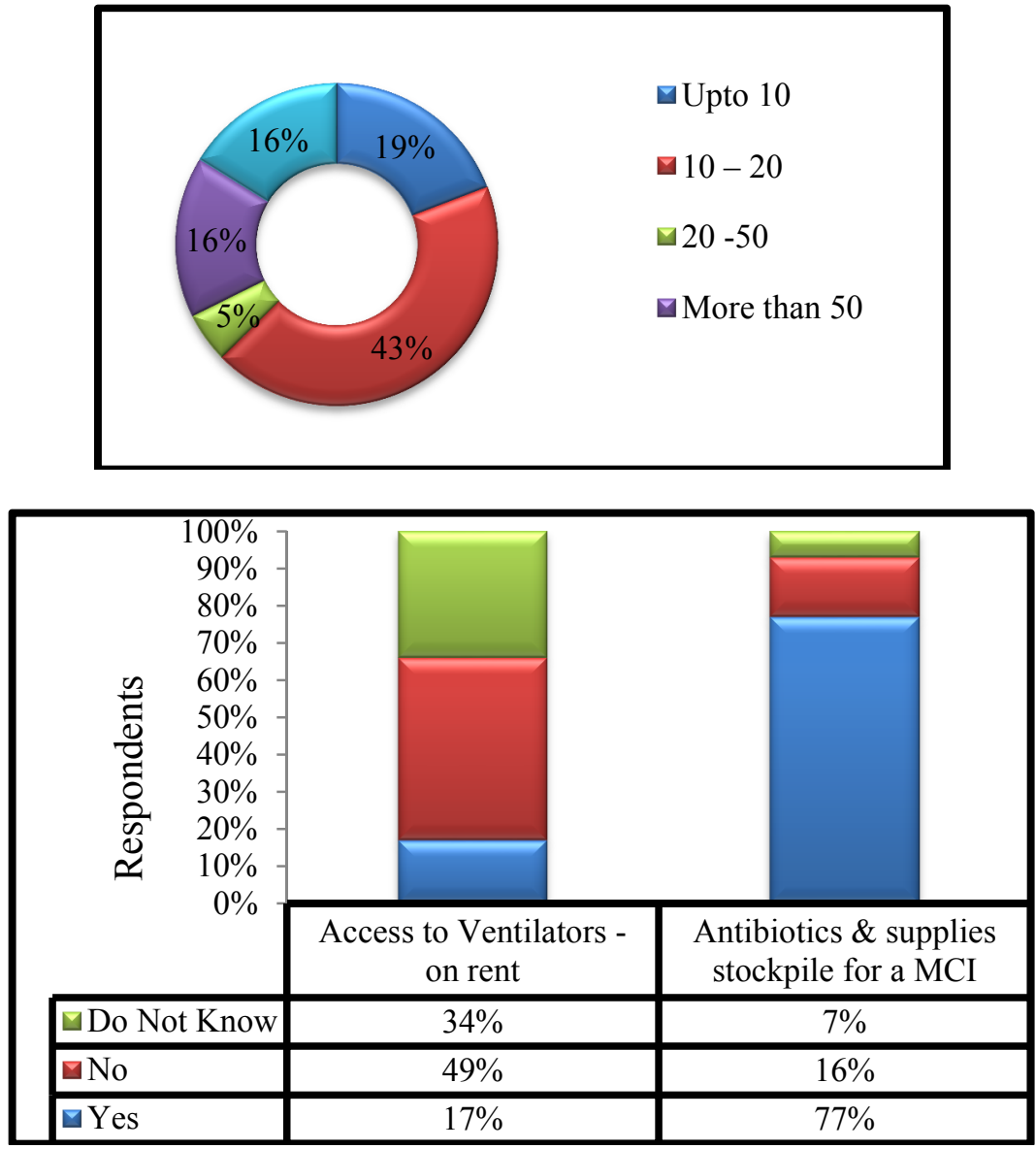

Figure 10 Logistics and Supply Management: Quality of Functional Ventilators (Field Survey, January - April 2017)

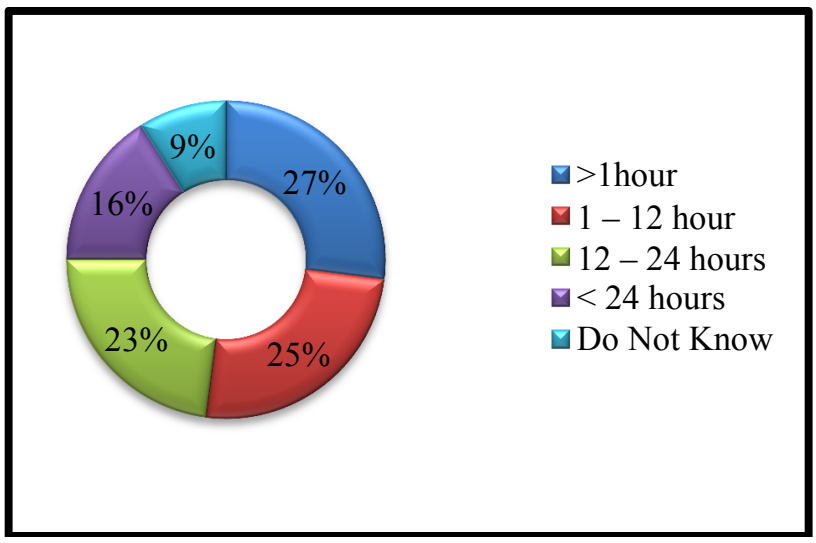

Figure 11 Logistics and Supply Management: Time to Replenish Critical Medical Resource (Field Survey, January - April 2017) 


\section{Post Disaster Recovery}

"Post-disaster recovery planning should be performed at the onset of response activities. Prompt implementation of recovery efforts can help mitigate a disaster's long-term impact on hospital operations" (Sorensen et al., 2011). Continued low scores varying from $14 \%$ to $32 \%$ on various questions pertaining to Post Disaster recovery is a matter of serious introspection for the health facilities. The fact that a majority of the health facilities have the capability to plan and conduct mass prophylaxis in case of an MCI is encouraging. The more or less complete absence of a Critical Incident Stress Management (CISM) programme (52\%) for the health facilities workers is something that needs to be tackled on a war footing. Last but not the least, the inadequate $(45 \%)$ availability of facilities for proper examination, care and disposal of mortal remains is also a matter of concern and must be remedied as soon as possible.

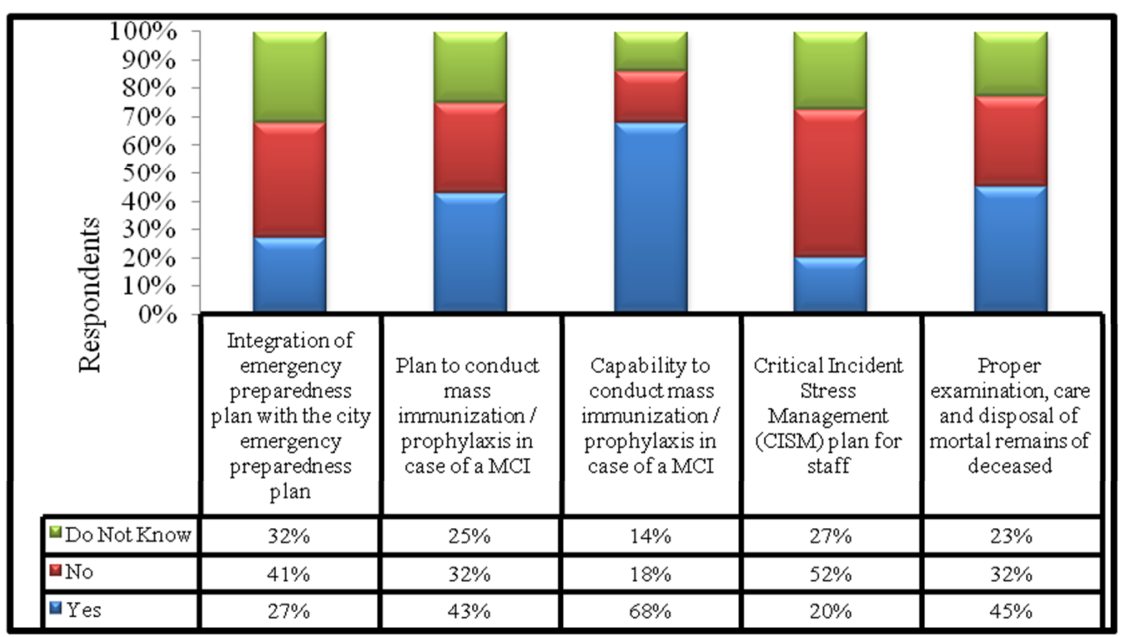

Figure 12 Post Disaster Recovery

(Field Survey, January - April 2017)

\section{Conclusion and Suggestions}

A close analysis of the study shows that a majority $(75 \%)$ of the health facilities in Chandigarh have documented preparedness plans, provide specific preparedness education/training (34\%), have dedicated facilities for decontamination $(25 \%)$, and adequate pharmaceutical plans and supplies (77\%) for the treatment of victims in the event of biological disasters. However, over half $(54.5 \%)$ of the health facilities could not provide any answer pertaining to their planned surge capacity (supplies, equipment, staff, patient beds, etc.). In general, health facilities in Chandigarh, like a number of health facilities throughout the country, are still not adequately prepared to manage victims of biological disasters which consequently may result in the loss of hundreds or even thousands of lives. Therefore, health facilities continue to require substantial resources at the local, State, and national levels in order to be "truly" prepared. These findings mirror those arrived at by Wetter et al 2001, where they have also concluded that "The current state of hospital preparedness in these 4 northwestern states for managing victims of chemical and biological terrorism is 
generally not adequate to support the present strategy of the Domestic Preparedness Program" (Wetter et al., 2001). Clearly, though efforts have been made to improve the preparedness of health facilities in the city, there are still tremendous gaps between these efforts and the preparedness status of health facilities as evident from the findings in this study. Therefore, healthcare executives and policymakers should utilize the findings in this study to create a broader forum at the local, district, state and central levels for discussions about the critical preparedness issues facing health facilities.

\section{References}

1. Ackerman, G. A., \& Pinson, L. E. (2014). An Army of One: Assessing CBRN Pursuit and Use by Lone Wolves and Autonomous Cells. Terrorism and Political Violence, 26(1), 226-245. https://doi.org/10.1080/09546553.2014.849945

2. Alexander, D. A., \& Klein, S. (2003, December). Biochemical terrorism: Too awful to contemplate, too serious to ignore - Subjective literature review. British Journal of Psychiatry. The Royal College of Psychiatrists. https://doi.org/10.1192/bjp.183.6.491 Alexander, D. A., \& Klein, S. (2006). The challenge of preparation for a chemical, biological, radiological or nuclear terrorist attack. Journal of Postgraduate Medicine, 52(2), 126-131. Retrieved from http://www.ncbi.nlm.nih.gov/pubmed/16679677

3. Bennett, R. L. (2006). Chemical or biological terrorist attacks: an analysis of the preparedness of hospitals for managing victims affected by chemical or biological weapons of mass destruction. International Journal of Environmental Research and Public Health, 3(1), 67-75. https://doi.org/10.3390/ijerph2006030008

4. Bhardwaj, J. (2010). Chemical, Biological, Radiological, and Nuclear disaster management. Journal of Pharmacy and Bio allied Sciences, 2(3), 157. https://doi.org/10.4103/0975-7406.68492

5. Bupesh, G., Sivasubramanian, S., Sakthivadivel, M., Gunasekeran, P., \& Raman, K. (2014). Biological Disaster, Prevention and Rescue. Journal of Management and Science, 4(4), 2249-1260.

6. Calder, A., \& Bland, S. (2015). Chemical, biological, radiological and nuclear considerations in a major incident. Surgery (United Kingdom), 33(9), 442-448. https://doi.org/10.1016/j.mpsur.2015.07.006

7. Centre for Disease Control and Prevention/: CDC. (2002). CDC - Bioterrorism and Emergency Readiness/: Competencies for All Public Health Workers. New York, NY 10032. Retrieved from http://training.fema.gov/emiweb/downloads/bioterrorism and emergency readiness.pdf

8. Chandigarh Administration. (2015a). Chandigarh Disaster Management Plan.

Chandigarh Master Plan - 2031. Retrieved from http://chandigarh.gov.in/cmp2031/disaster.pdf

9. Chandigarh Administration. (2015b). Chandigarh Master Plan - 2031/: Demography. Chandigarh Master Plan - 2031. Retrieved from http://chandigarh.gov.in/cmp2031/demography.pdf

10. Chandigarh Disaster Management Authority. (2014). Multihazard Disaster Management Plan for Chandigarh (Draft). 
11. FEMA. (2009). FEMA Acronyms Abbreviations \& Terms (FAAT). U.S. Department of Homeland Security/: Federal Emergency Management Agency. FEMA. Retrieved from https://www.fema.gov/pdf/plan/prepare/faatlist 07 09.pdf

12. FEMA - Federal Emergency Management Agency. (2014). Are You Ready? An In-depth Guide to Citizen Preparedness (1st Ed.). Jessup, USA. Retrieved from https://www.fema.gov/pdf/areyouready/areyouready_full.pdf

13. Government of India. (2011). Census of India 2011/: Provisional Population Totals - Chandigarh. Chandigarh. Retrieved from http://censusindia.gov.in/2011-prov-results/data_files/chandigarh/Provisional Pop. Paper-I-Chandigarh U.T.pdf

14. ICPO - Interpol. (2007). Bioterrorism Incident/: Pre Planning and Response Guide. Lyon, France. Retrieved from http://www.ndma.gov.pk/Docs/BioTerrorismGuideINTERPOL.pdf

15. Indiatimes.com. (2015). Scaling up healthcare facilities in Chandigarh, Health News, ET Health World. Retrieved February 18, 2017, from http://health.economictimes.indiatimes.com/news/industry/scaling-uphealthcare-facilities-in-chandigarh/46918474

16. Kaul, D., Ayaz, M., \& Lohitkumar, S. (2005). Disaster Management in India. Catastrophic Risks and Insurance, 381-392. https://doi.org/http://dx.doi.org/10.1787/9789264009950-22-en

17. Ministry of Home Affairs. (2013). Comptroller and Auditor General (CAG) Report/: Disaster Preparedness of India. Report Number 5 of 2013 (Vol. 1). https://doi.org/10.1017/CBO9781107415324.004

18. Ministry of Law and Justice/: Legislative Department. Disaster Management Act - 2005 (2005). India: Ministry of Law and Justice (Legislative Department), Government of India.

19. National Centre for Disaster Management. (2002). The Report of High Powered Committee on Disaster Management, 1-316. Retrieved from http://www.saarcsadkn.org/PDF/HPC_Report.pdf

20. National Disaster Management Authority. (2008). National Disaster Management Guidelines - Management of Biological Disasters.

21. National Disaster Management Authority. (2013). National Disaster Management Guidelines/: Hospital Safety (Draft). New Delhi. Retrieved from http://www.ndma.gov.in/images/pdf/NDMAhospitalsafety.pdf

22. National Executive Council (NEC) - Ministry of Home Affairs/: Government of India. (2013). National Disaster Management Plan. New Delhi. Retrieved from http://ndmindia.nic.in/NDMP_2300216.pdf

23. Ramesh, A. C., \& Kumar, S. (2010). Triage, Monitoring, and Treatment of Mass Casualty events involving CBRN agents. Journal of Pharmacy and Bio allied Sciences, 2(3), 239-247. https://doi.org/10.4103/0975-7406.68506

24. Richardt, A., \& Sabath, F. (2013). A Glance Back - Myths and Facts about CBRN Incidents. In CBRN Protection: Managing the Threat of Chemical, Biological, Radioactive and Nuclear Weapons (pp. 1-38). Wiley-VCH. https://doi.org/10.1002/9783527650163.ch1

25. Ryan, J., \& Glarum, J. (2008). Biosecurity and Bioterrorism/: Containing and Preventing Biological Threats. (THE BUTTERWORTH-HEINEMANN 
HOMELAND SECURITY SERIES, Ed.) (First). Burlington MA: Elsevier. Retrieved from https://booksite.elsevier.com/samplechapters/9780750684897 /Sample_Chapters/01 Front_Matter.pdf

26. Sandstrom, B. E., Eriksson, H., Norlander, L., Thorstensson, M., \& Cassel, G. (2014). Training of public health personnel in handling CBRN emergencies: A table-top exercise card concept. Environment International, 72, 164-169. https://doi.org/10.1016/j.envint.2014.03.009

27. Sorensen, B. S., Zane, R. D., Wante, B. E., Rao, M. B., Bortolin, M., \& Rockenschaub, G. (2011). WHO - Hospital Emergency Response Checklist. Copenhagen. Retrieved from http://www.euro.who.int/_data/assets/pdf_file/0008/268766/Hospitalemergency-response-checklist-Eng.pdf

28. Thavaselvam, D., \& Vijayaraghavan, R. (2010). Biological warfare agents. Journal of Pharmacy \& Bio allied Sciences, 2(3), 179-88. https://doi.org/10.4103/0975-7406.68499

29. Tonev, S., Kanev, K., \& Dishovsky, C. (2010). Medical Management of Chemical and Biological Casualties. JMedCBR, 8(8), 293-350.

30. United Nations International Strategy for Disaster Reduction. (2005a). Hyogo Framework for Action 2005-2015. In World Conference on Disaster Reduction (pp. 1-25). https://doi.org/10.1017/CBO9781107415324.004

31. United Nations International Strategy for Disaster Reduction. (2005b). Summary of the Hyogo Framework for Action 2005-2015. In World Conference on Disaster Reduction. Retrieved from www.unisdr.org

32. Wetter, D. C., Daniell, W. E., \& Treser, C. D. (2001). Hospital preparedness for victims of chemical or biological terrorism. American Journal of Public Health, 91(5), 710-716. https://doi.org/10.1097/00006454-200111000-00030

\section{About Our Authors}

Col Gaurav Bhatia is a serving officer of the Indian Army - he was commissioned into the Armoured Corps in 1990. He is a Gold Medal winner from Panjab University, Chandigarh for the Master Degree in Disaster Management. Col Bhatia, is a Research Scholar with an abiding interest in the field of Disaster Management and Disaster Risk Reduction with a special interest in the realm of CBRN aspects of manmade disasters.

Namrata Sandhu has authored one book and 39 research papers/articles that have published in journals such as Journal of Human Values, Journal of Marketing and Communication, International Journal of Humanities and Social Science, AsiaPacific Business Review, International Journal of Business and Social Science, Indian Journal of Finance etc. She has recently won the best research paper award at the Indian Institute of Management, Bangalore (2015 IMRA-IIMB International Conference). She is the recipient of the AIMS International Outstanding Young Woman Researcher Award. At present, she is working on two industry sponsored consultancy projects. 